\title{
Recognition and Management of Oral Health Problems in Older Adults by Physicians: A Pilot Study
}

\section{Thomas V.Jones, MD, MPH, Mitchel J. Siegel, DDS, and John R. Scbneider, MA}

Oral health problems are among the most common chronic health conditions experienced by older adults. Healthy People 2000, an initiative to improve the health of America, has selected oral health as a priority area. ${ }^{1}$ About 11 of 100,000 persons have oral cancer diagnosed every year. ${ }^{2}$ The average age at which oral cancer is diagnosed is approximately 65 years, with the incidence increasing from middle adulthood through the seventh decade of life. ${ }^{1-3}$ Even though the mortality rate associated with oral cancer (7700 deaths annually $)^{4}$ ranks among the lowest compared with other cancers, many deaths from oral cancer might be prevented by improved case finding and referral. Because oral cancers and other important conditions can be detected with a simple oral cavity examination, the US Preventive Services Task Force and the American Cancer Society both recommend oral screening for all adults. ${ }^{2}$

An important question yet unanswered is how best to implement screening oral examinations. Older adults have one of the lowest utilization rates of dental services for any age group. ${ }^{5}$ Only 35 percent of patients 75 years or older visit their dentist at least annually, but nearly 90 percent see physicians. ${ }^{6}$ Physicians, however, are often limited in their awareness of the spectrum and clinical relevance of oral health problems in their older patients. ${ }^{4}$

Several studies have cited the need to improve and integrate educational standards on oral health care in primary care physicians' training programs. This emphasis is due in part to assessments

Submitted, revised, 18 March 1998.

From the Department of Internal Medicine, University of Nebraska Medical Center (TVJ, JRS), Omaha, and the Veterans Administration Medical Center (MJS), Salisbury, NC. Reprints are not available.

Supported in part by a grant from the Section of Geriatrics and Gerontology, Department of Internal Medicine, University of Nebraska Medical Center.

Presented in part at the annual meeting of the American Geriatrics Society, New Orleans, November 1993. of the nation's current and future health care needs, the steady increase in the older adult population, and the generally high access elderly persons have to medical care provided by family physicians and internists. $5,7,8$ Currently there is very little information about the ability of family physicians or internists, such as geriatricians, to assess the oral health of older patients. We conducted this preliminary study to determine how family physicians and geriatricians compare with each other and with general practice dentists in their ability to recognize, diagnose, and perform initial management of a wide spectrum of oral health problems seen in older adults.

\section{Methods}

Clinicians included in the study were a convenience sample of 4 family physicians and 4 internist geriatricians (all 8 were academic medical center faculty), and 4 community-based general practice dentists. The 8 physicians were trained at various institutions. Geriatricians were fellowship trained and board certified in internal medicine and geriatric medicine. Family physicians were all board certified in family practice, without certification in geriatrics. None of the physicians had formal instruction on oral health problems; however, the geriatricians had limited experience working with a geriatric dentistry fellow in a clinical practice setting.

Participants completed a survey to establish their level of training, characteristics of their clinical practice, and amount of formal instruction in oral health. They also completed a 32-item multiple choice examination designed to assess their general knowledge of common oral disease in older adults. Questions were drawn from references on oral health such as textbook chapters or summary review articles written for physicians. ${ }^{3,6,7}$

On separate days the physician group and the dentist group were each shown a series of 30 color slides, of which 27 portrayed a wide spectrum of 
Table 1. Degree of Appropriateness for Referral of Oral Disease and the Percentage of Accuracy of Diagnoses.

\begin{tabular}{|c|c|c|}
\hline $\begin{array}{l}\text { Diagnosis } \\
\text { by Need } \\
\text { for Referral }\end{array}$ & $\begin{array}{c}\text { Family } \\
\text { Physicians } \\
\text { Percent } \\
\text { Accurate } \\
\end{array}$ & $\begin{array}{c}\text { Geriatricians } \\
\text { Percent } \\
\text { Accurate } \\
\end{array}$ \\
\hline \multicolumn{3}{|l|}{ Immediate } \\
\hline Squamous carcinoma & 100 & 100 \\
\hline Severe periodontitis or caries & 100 & 100 \\
\hline Leukoplakia & 100 & 75 \\
\hline Traumatic ulcer & 50 & 50 \\
\hline Erythroplakia & 50 & 25 \\
\hline Snuff lesion & 25 & 25 \\
\hline Gumboil (abscess) & 25 & 0 \\
\hline \multicolumn{3}{|l|}{ Intermediate } \\
\hline Moderate periodontitis & 75 & 100 \\
\hline Major aphthae & 50 & 75 \\
\hline Xerostomia & 50 & 75 \\
\hline Lichen planus & 25 & 75 \\
\hline Papilloma & 25 & 75 \\
\hline Mucocele & 50 & 75 \\
\hline Papillary hyperplasia & 25 & 50 \\
\hline Denture stomatitis & 25 & 50 \\
\hline Epulis fissuratum & 0 & 0 \\
\hline \multicolumn{3}{|l|}{ Unnecessary } \\
\hline Torus palatinus & 100 & 100 \\
\hline Mild gingivitis & 100 & 100 \\
\hline Candidiasis & 100 & 100 \\
\hline Lingual varices & 100 & 100 \\
\hline Angular cheeses & 75 & 100 \\
\hline Herpes labialis & 75 & 75 \\
\hline Torus mandibularis & 50 & 100 \\
\hline Geographic tongue & 100 & 25 \\
\hline Fordyce granules & 0 & 25 \\
\hline Nicotine stomatitis & 0 & 0 \\
\hline Foliate papillae & 0 & 0 \\
\hline
\end{tabular}

oral lesions and disease (Table 1); the remaining 3 slides depicted normal oral cavities. Before the slides were presented, the participants were informed that some slides would be normal but were not told how many. Most of the slides were from a teaching collection developed by the University of Missouri-Kansas City School of Dentistry, ${ }^{9}$ supplemented by slides from the teaching files of one of the authors (MS). Each abnormal slide included a primary, more obvious lesion or condition, but several had secondary abnormalities. For example, a slide of leukoplakia might also show a mild degree of gingivitis. The final standards for description of the abnormality, diagnosis, and treatment for each case were based on a consensus between two of the investigators (TJ, MS) and the independent review of an oral pathologist.

Participants were seated apart from each other and informed that group discussion was not permitted, nor would there be any feedback from the investigators during testing. The physicians and dentists reviewed each slide for 2 minutes, were asked to decide whether the slide showed normal or abnormal conditions, and then given an additional 30 seconds to complete their responses before moving on to the next slide. If the condition on the slide was judged to be abnormal, the participants were asked to record a description and a diagnosis for each abnormality seen and to give their management recommendations. Two of the investigators (TJ, MS) judged the accuracy and appropriateness of the responses.

\section{Results}

Descriptive data included years in clinical practice, percentage of time spent in patient care, and an estimate of the percentage of patients aged 65 years and older in their practices (Table 2). As expected, the community-based dentists spent almost all of their time in patient care activities, approximately twice as much as the family physicians and geriatricians, all of whom were in an academic setting. Nearly all patients (98 percent) cared for by geriatricians were 65 years or older compared with an average of less than 30 percent for family physicians and dentists.

Scores on the 32-item multiple choice examination were relatively similar, with a mean of 17.5 correct responses for the family physicians ( 55 percent score, range 17 to 18$) ; 19.5$ correct responses for the geriatricians (62 percent score, range 19 to 21 ); and 19 correct responses for the general dentists (59 percent score, range 16 to 23).

A comparison was made between the three

Table 2. Clinician and Practice Characteristics.

\begin{tabular}{lccc}
\hline Characteristics & Family Physicians, Mean (Range) & Geriatricians, Mean (Range) & Dentists, Mean (Range) \\
\hline Years in practice, $\mathrm{n}$ & $11(4-15)$ & $7.8(2-3)$ & $10(5-15)$ \\
Time in patient care, \% & $53(20-80)$ & $50(30-60)$ & $99(99-100)$ \\
Patients 265 years, \% & $25(5-60)$ & $98(95-100)$ & $29(10-60)$ \\
\hline
\end{tabular}


Table 3. Comparison of Clinician Performance.

\begin{tabular}{|c|c|c|c|c|c|c|}
\hline \multirow{2}{*}{$\begin{array}{l}\text { Performance } \\
\text { Factors }\end{array}$} & \multicolumn{2}{|c|}{ Family Physicians } & \multicolumn{2}{|c|}{ Geriatricians } & \multicolumn{2}{|c|}{ General Dentists } \\
\hline & $\%$ & (Range) & & (Range) & $\%$ & (Range) \\
\hline Description & 84 & $(70-93)$ & 94 & (90 - 97) & 95 & $(93-97)$ \\
\hline Diagnosis & 53 & $(43-67)$ & 58 & $(47-63)$ & 78 & $(70-83)$ \\
\hline Management & 68 & $(57-80)$ & 70 & $(63-77)$ & 82 & $(77-90)$ \\
\hline Immediate referral $^{*}$ & 89 & $(86-100)$ & 79 & $(57-100)$ & & \\
\hline Unnecessary referral $^{\dagger}$ & 27 & $(0-50)$ & 25 & $(17-33)$ & & \\
\hline Incorrect diagnosis and management ${ }^{\ddagger}$ & 53 & $(47-60)$ & 62 & $(46-73)$ & & \\
\hline
\end{tabular}

Note: values shown are mean percentages of correct responses, with ranges in parentheses.

*Decision to refer for the 7 cases judged to warrant immediate referral.

tDecision to refer for the 11 cases judged not to warrant any referral.

‡Selection of an inappropriate management choice when an incorrect diagnosis was made, for all 30 cases.

groups of clinicians on description, diagnosis, and management of oral health problems (Table 3). The physicians were able to provide acceptable descriptions of the abnormalities an average of 89 percent of the time. The rate of correct diagnoses averaged only 55 percent, however, for the family physicians and geriatricians, compared with 78 percent for the dentists. Although physicians' diagnoses were only moderately accurate, correct or appropriate treatment decisions were made nearly 70 percent of the time. Some of the conditions (ie, epulis fissuratum, nicotine stomatitis, and foliate papillae) were particularly difficult for the family physicians and geriatricians to diagnose, as reflected by very low rates of diagnostic accuracy (Table 1). Unnecessary referral, defined as when physicians could have adequately managed the condition themselves, occurred an average of 26 percent of the time.

Seven of the cases were judged to warrant immediate referral to a dental practitioner for more urgent treatment. Of these 7 cases, family physicians and geriatricians diagnosed 36 percent and 46 percent incorrectly, respectively. Including both correct and incorrect diagnoses for the 7 more urgent conditions, the decision to refer patients was made 90 percent of the time by family physicians and 79 percent of the time by geriatricians. When a misdiagnosis was made, family physicians reached the correct treatment decision of immediate referral 67 percent of the time compared with 56 percent for geriatricians.

\section{Discussion}

The likelihood is low that older adults will seek dental services in contrast to care from a family physician or internist such as a geriatrician. Thus, it is important that physicians caring for older adults possess an awareness of oral cavity abnormalities and the skills needed to recognize and respond appropriately to them. This study assessed the ability of family physicians and geriatricians to recognize, diagnose, and either treat or refer a wide range of oral health problems found in older adults.

Overall, our findings showed that family physicians and geriatricians, although comparable in their ability to assess dental conditions, did so at an unacceptably low level of accuracy. Many of their diagnostic errors, moreover, were associated with a relatively high rate of incorrect or inappropriate treatment and referral decisions.

Of the $\mathbf{2 7}$ oral abnormalities that appeared on the slides, 7 were considered to warrant immediate referral. Of concern, the physicians' descriptions and diagnoses were relatively inaccurate for several of these cases. For example, erythroplakia, a potentially premalignant condition, was misdiagnosed an average of 62 percent of the time. Conversely, however, the decision to refer the patient immediately was made approximately 85 percent of the time. This finding suggests a tendency for the physicians to refer when in doubt of their diagnosis, which was further borne out by a high likelihood for recommending referral for the most frequently misdiagnosed conditions that did not warrant any referral. Such a strategy might in some instances lead to unnecessary referrals for nonpathologic findings or minor conditions, but for dealing with potentially more urgent problems, it is a strategy to be commended.

Consistent with their similar ability to recognize oral cavity abnormalities on the slides, the family physicians and geriatricians were also rela- 
tively similar in their general knowledge of oral health problems as measured by scores on the multiple choice examination. Surprisingly, the dentists did not appear to do much better than the physicians on the multiple choice examination; moreover, the dentists had more difficulty with management than was expected.

Although our results indicate a need for increased awareness and knowledge in oral health care for the older person, there were limitations to the study. First, the sample of participants was small and based on convenience, rather than drawn by random sampling. Second, the participants were asked to respond to slides of photographs. The relative contributions of being able to inspect lesions visually from a variety of angles and by palpation or of listening to patients' reports of symptoms were not assessed.

Despite these limitations, we conclude that family physicians and geriatricians might need additional training if they are to effectively screen for and make initial management decisions about geriatric dental conditions. Finding additional time for emphasis on oral health problems in already full undergraduate and graduate curricula could prove to be a serious challenge, however. Family physicians compared favorably with and in many instances exceeded the geriatricians' performance. It cannot be assumed, therefore, that conventional training and increased patient contact with elderly adults will in itself enhance the ability of physicians to recognize and manage oral health problems. Emphasis should be placed on oral examination instruction that stresses recognition of urgent or critical abnormalities, leading to appropriate referral even when the physician is unable to establish an exact diagnosis.

We would like to thank Donald $M$. Cohen for his comments on slide preparation and assistance in the review of the descriptions, diagnoses, and treatments of the oral abnormalities given by the 12 participants.

\section{References}

1. Dolan TA. Is dental education in step with current geriatric health promotion initiatives? J Dent Educ 1992;56:632-5.

2. Frame PS, Rosati C. Screening for oral cancer. In: Report of the US Preventive Services Task Force. Guide to clinical preventive services. 2nd ed. Baltimore: Williams \& Wilkins, 1996:175-80.

3. Dolan TA, Monopoli MP, Kaurich MJ, Rubenstein LZ. Oral diseases in older adults. J Am Geriatr Soc 1990;38:1239-50.

4. Westman EC, Duffy MB, Simel DL. Should physicians screen for oral disease? A physical examination study of the oral cavity. J Gen Intern Med 1994;9: 558-62.

5. Pyle MA, Terezhalmy GT. Oral disease in the geriatric patient: the physician's role. Cleve Clin J Med 1995;62:218-26.

6. Fedele DJ, Jones JA, Niessen LC. Oral cancer screening in the elderly. J Am Geriatr Soc 1991;39: 920-5.

7. Baum BJ, Ship JA. Diseases of the organ systems: the oral cavity. In: Hazzard WR, Andres R, Bierman EL, Blass JP. Principles of geriatric medicine and gerontology. 2nd ed. New York: McGraw-Hill, 1990:41321.

8. Burt BA. Epidemiology of dental diseases in the elderly. In: Baum BJ. Clinics in geriatric medicine: oral and dental problems in the elderly. Philadelphia: WB Saunders, 1992:447-59.

9. Dunlap C, Barker BF. Oral lesions: An illustrated quick-reference guide to diagnosis and treatment. 3rd ed. Colgate-Hoyt/Gel-Kam. 1991. 